GU J Sci, Part C, 6(4): 753-764 (2018)

Gazi Üniversitesi
Fen Bilimleri Dergisi
PART C: TASARIM VE TEKNOLOJI
http://dergipark.gov.tr/gujsc

\title{
Araçlarda Su Sızdırmazlık Testi için Otomasyon Sistem Tasarımı ve Uygulaması
}

\author{
Murat AYAZ1 , Koray ERHAN², Engin ÖZDEMIR ${ }^{2, *}$ \\ ${ }^{1}$ Kocaeli Üniversitesi, Uzunçiftlik Nuh Çimento Meslek Yüksek Okulu, 41180, Kartepe/KOCAELI \\ ${ }^{2}$ Kocaeli Üniversitesi, Teknoloji Fakültesi, Enerji Sistemleri Mühendisliği Bölümü, 41380, İzmit/KOCAELi்
}

\begin{abstract}
$\underline{\mathbf{O ̈}_{z}}$
Makale Bilgisi

Bașvuru: 02/05/2018

Düzeltme: $22 / 07 / 2018$

Kabul: $07 / 08 / 2018$

Bu çalışmada, bir otomotiv üretim tesisinde üretilen aracın kalite kontrol testlerinden biri olan basınçlı su ile sızdırmazlık testinin, kesintisiz ve seri üretimi aksatmayacak şekilde gerçekleştirilmesini sağlayacak bir otomasyon sistem tasarımı ele alınmaktadır. Tasarlanan basınçlı su testi sisteminde bütün araçların aynı standardı sağlayacak şekilde, eşit sürelerde ve tamamen kurutulduktan sonra bir sonraki istasyona ulaşması sağlanmaktadır. Bu işlemler gerçekleştirilirken minimum enerji ve su sarfiyatı yapılması hedeflenmektedir. $\mathrm{Bu}$ amaçla, geleneksel sistemlere göre bazı tasarım değişiklikleri yapılmaktadır. Böylece \% 40’lara varan enerji ve \% 80'e varan su tasarrufu sağlanmaktadır. Ayrıca, test sistemi operatörlerden bağımsız hale getirilerek üretim sürecinin kesintiye uğraması veya sistemin gereksiz yere çalışması önlenmektedir.
\end{abstract}

\section{Anahtar Kelimeler \\ Endüstriyel otomasyon sistemleri \\ Otomotiv uygulamalar $P L C$ \\ Araç sızdırmazlık testi}

\section{Keywords}

\section{Industrial automation} systems

Automotive applications $P L C$

Water leakage test of vehicles

\section{Design and Implementation of Automation System for Water Leakage Test in Vehicle}

\begin{abstract}
In this study, design and implementation of automation system for water leakage test, which is one of the quality control tests, in vehicle is explained in detail in order to ensure continuous operation and without interruption of serial production line. Before vehicles are transferred to the next assembly station, it is ensured that all the vehicles are tested at the same standard pressure values and at equal duration in the proposed pressurized water test system. The minimum energy and water consumption has been aimed during carrying out these processes. For this purpose, some design changes have been made compared to conventional systems. Thus, up to $40 \%$ energy and up to $80 \%$ water savings have been achieved. In addition, by making the system independent from the operators, the proposed automation system prevents the production process from being interrupted or the system running unnecessarily.
\end{abstract}

\section{GIRIŞ (INTRODUCTION)}

İki asırdan fazla zamandır insanlığın hayatında olan sanayileşme ile modern çağın teknolojisini yakalamak için oldukça yoğun uğraşlar söz konusu olmuştur. Sanayileşmenin getirdiği teknolojik yeniliklerle beraber, hayatın insan yaşamı için kolaylaştırılması sağlanmaktadır. İnsan hayatını kolaylaştırmak için endüstride, yönelimde ve bilimsel işlerde hedeflenen ilk nokta; insan gücü olmadan işlerin otomatik olarak yapılmasıdır [1-4]. Teknolojinin gelişmesiyle artan rekabet; beraberinde hızlı, kaliteli ve standartlara uygun olmayı da getirmiştir. $\mathrm{Bu}$ sebeptendir ki; üretim sadece insan aracıllğıyla değil, makine ve insan gücünün birleşmesiyledir. Günümüzün yaşam standartları göz önüne alındığında; gelişmekte olan dünya da nüfus artış1 ile birlikte otomotiv sektöründe de bir büyüme görülmektedir. Tüketicilerin ihtiyacını karşılamak amacıyla otomotiv sektöründeki firmalar, farklı ve orijinal görünümlerinin yanı sıra, sağlam ve kaliteli ürün ortaya koymak için de yarış haline girmişlerdir.

Otomotiv sektörü, araştırma-geliştirme faaliyetlerinin sürekli olarak devam ettiği ve her geçen gün yeni bir teknolojinin entegre edildiği bir alandır. Otomotiv üreticileri pazardaki diğer üreticiler ile rekabet 
edebilmek için gerek üretim maliyetlerini gerekse de üretim standartlarını sürekli olarak iyileştirmek zorundadırlar. $\mathrm{Bu}$ durum otomotiv sektöründe, otomasyon sistemlerinin daha yaygın bir biçimde kullanılmasını kaçınılmaz hale getirmektedir. Otomotiv sektörü endüstrinin en temel dallarından biridir. Otomotiv sektörü için, yüksek adetli üretim yapabilmek adına seri üretim mantığının ortaya çıktığı ilk alan denilebilir. Tarihe bakıldığında ilk otomasyon adımlanı, otomotiv alanında kendini göstermiştir. Yapılan işlerin kontrolünde ve sıralı işlem yapabilme özelliğiyle büyük önem arz eden otomasyon; elektronik, mekanik ve bilgisayar tabanlı kolektif bir teknoloji sistemidir. Otomotiv sektörü özelinde bakıldığında, gerek üretim kalitesinin geliştirilmesi gerekse de üretim hızının arttırılması üzerine birçok otomasyon sistemi geliştirilmiştir.

$\mathrm{Bu}$ bağlamda literatüre bakıldığında, aracın yakıt deposunu araca monte etmek için gerçekleştirilen otomasyon sistemi ile hem güvenli hem de operatör iş yükünü hafifleten bir sistem kurulmuştur [5]. Benzer şekilde otomotiv sektörünün omurgasını teşkil eden kaynak işlemi de günümüzde neredeyse tamamen robotlar tarafından yapılmaktadır [6]. Bu sayede insan kaynaklı olası işçilik hataları ortadan kaldırılarak, her araç için eş kaynak profili ortaya konulmaktadır [7]. Diğer bir tez çalışmasında ise Türkiye'deki otomotiv sektöründe yer alan imalat otomasyonu incelenmiştir. Yapılan anket çalışmaları sonucunda, otomasyon sistemlerinin insan yoğun iş gücü gereksinimini azalttığ 1 ancak bununla birlikte çalışanlar üzerinde stres, dışa bağımlılık ve yetkin iş gücü noksanlığı gibi bir takım olumsuzluklar da getirdiği bildirilmektedir [8].

$\mathrm{Bu}$ çalışma kapsamında, otomotiv üretim bandı kesintiye uğratılmadan ve her bir aracı aynı standart değerler atlında sıvı sızdırmazlık testinin gerçekleştirilebilmesi için bir otomasyon sistemi tasarımı ve uygulaması ele alınmaktadır. Araç montaj hattının sonunda, üretim aşaması biten her bir aracın sızdırmazlık testinin yapılması önemli bir üretim - kontrol aşamasını teşkil etmektedir. Üretilen araçların yağmurlu havada veya kirlendikten sonraki temizlenme işlemi sırasında yüzeyine gelebilecek suyun, iç ortama sızıp sızmadığının tespitini yapabilmek için araca basınçlı su testi yapılmaktadır. Basınçlı su testinde kaçakların yanı sıra aracın ilgili malzemelerinin (körük, fitil, conta vs.) dayanıklılı̆̆ı da tespit edilir. Teste tabii tutulan araçlara sertliği düşürülmüş, tazyikli su uygulanır.

Tasarlanan test sisteminde, bir konveyöre gelen aracın sersör ile algılanması akabinde basınçlı suyun araca püskürtülmesi, bunun bitiminde de fanların devreye girip aracı kurutması işlemleri gerçekleşmektedir. Konveyörden aracın çıkmasından sonra, hattın sonundaki operatörün aracı gözle kontrol etmesi gerekir. Bu sayede aracın iç mekânında, bagaj ve motor haznesinde kaçak olup olmadığ 1 tespit edilir. Su alma ihtimali yüksek olan birleşim noktaları daha detaylı bir şekilde kontrol edilmektedir. Bu test işleminin ardından araç \%90-95 oranında kurutulmuş halde bir sonraki kalite kontrol birimine ulaşır.

\section{BASINÇLI SU TEST SISTEMI TASARIMI (PRESSURIZED WATER TEST SYSTEM DESIGN)}

Basınçlı su test sisteminde araç, yanları ve üstü kapalı bir kabine girmektedir. Bu kabinde basınçlı su çıkışının olduğu nozzle'lar bulunmaktadır. Bu nozzle'lar sayesinde araç, gündelik kullanımda karşılaşılabilecek zorlu koşulları simüle eden basınç değerinde ve çok noktadan su sızdırmazlık testine tabi tutulmaktadır. Şekil 1'de araç basınçlı su test sisteminin değişik açılardan perspektif görünüşleri verilmektedir.

Kabin içerisinde bulunan hareketli kolonlar ve hareketli kurutma fanlarının değişik açılardan perspektif görünüşleri Şekil 2'de görülmektedir. Basınçlı su testinin ardından aracın dış yüzeyinin kurutulması gerekmektedir. Kurutma işlemi için yine kabin içerisinde yüksek debili sabit ve hareketli fanlar bulunmaktadır. Bu fanlar kısa süre içerisinde aracın dış yüzeyini kurutarak, aracın sonraki istasyona kuru bir şekilde ulaşmasını sağlamaktadır. Gerçekleştirilen sistem çalışırken yıkama fıskiyelerinin ve kurutma fanlarının değişik açılardan perspektif görünüşleri Şekil 3'de verilmektedir. 

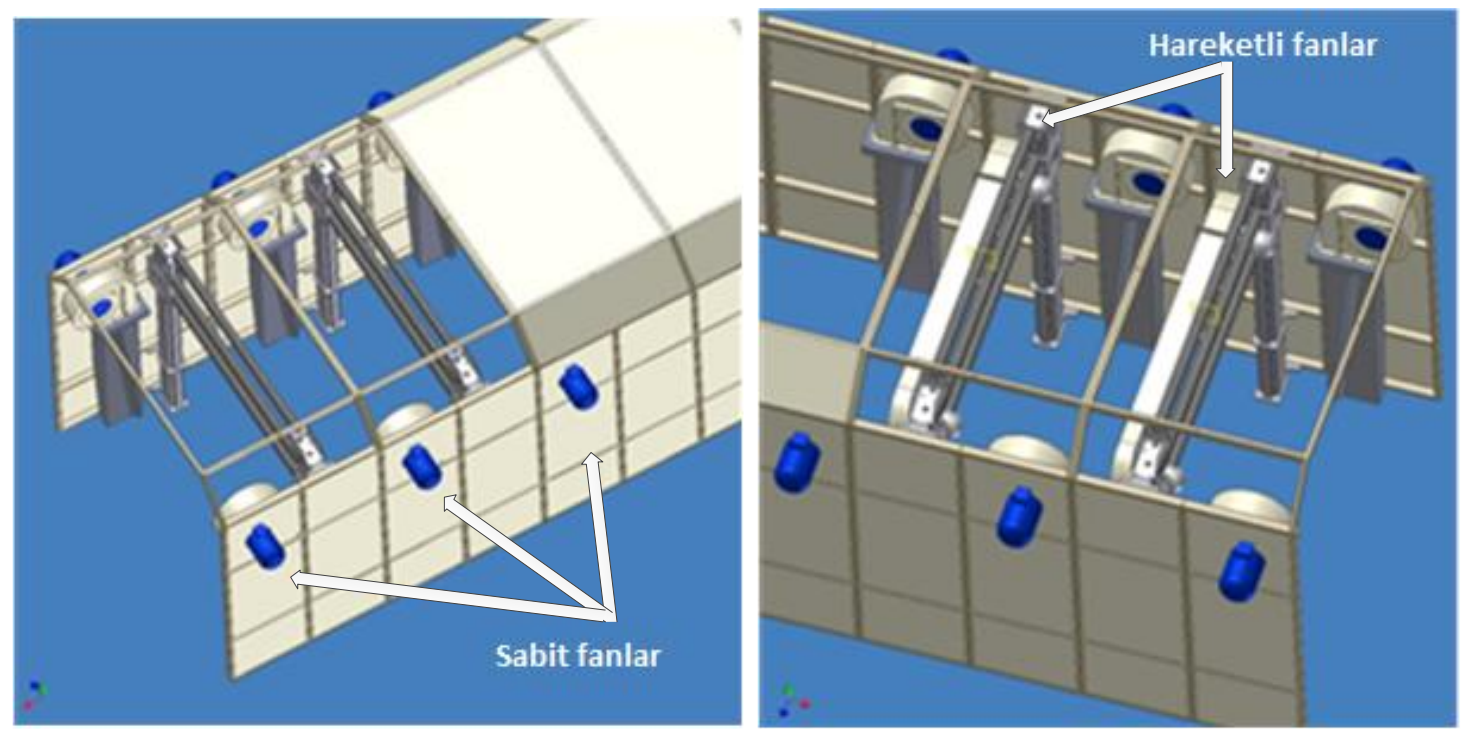

Şekil 1. Kabin çıkışındaki sabit ve hareketli kurutma fanlarının değisşik açılardan perspektif görünüşleri.
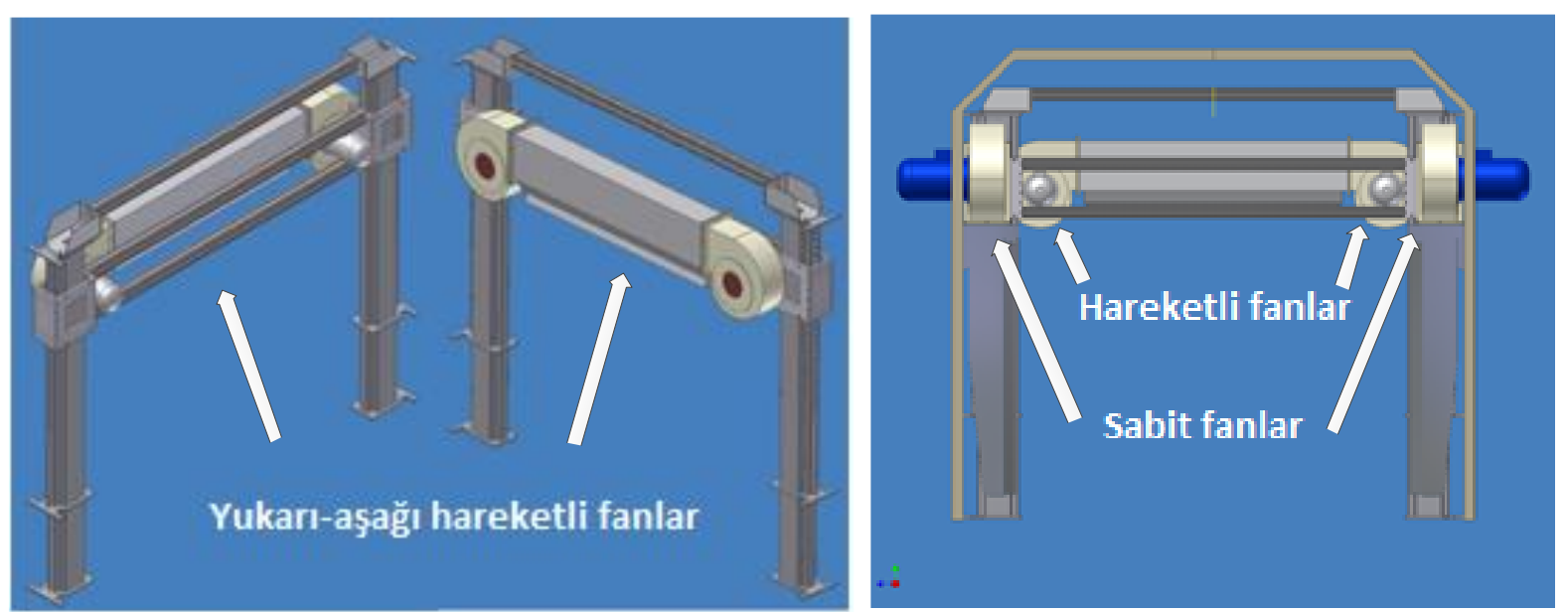

Şekil 2. Hareketli kurutma fanlarının değişik açılardan perspektif görünüşleri.

\subsection{Tahrik Sistemi Hesaplamaları ve Seçimi (Drive System Calculations and Selection)}

Tasarlanan sistemde kurutma işlemini gerçekleştiren hareketli fan sistemi, servo motorlar yardımı ile hareketini sağlamaktadır. Servo motorlar yardımıyla fanların araca olan mesafesi yüksek hassasiyet ile ayarlanabilmektedir. Hareketli fan sistemi Şekil 4'deki makara sistemine benzer şeklinde tasarlanmış olup, servo motorun seçimi bu hesaplamaların sonucuna göre gerçekleştirilmektedir.

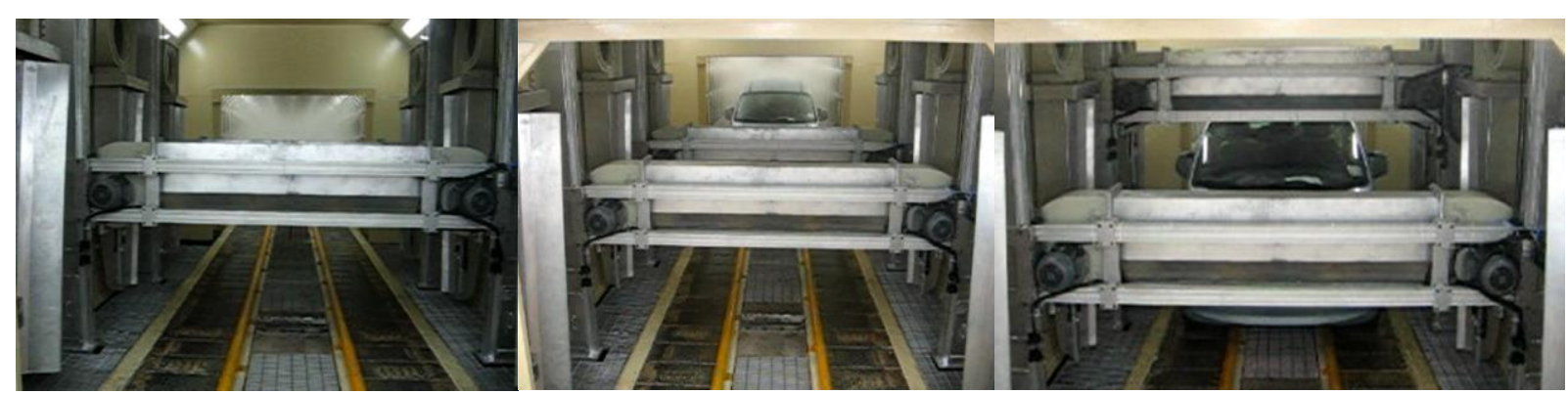

Şekil 3. Sistem çalışırken yıkama fiskiyeleri ve kurutma fan kolonlarının değişik açılardan perspektif görünüşleri. 


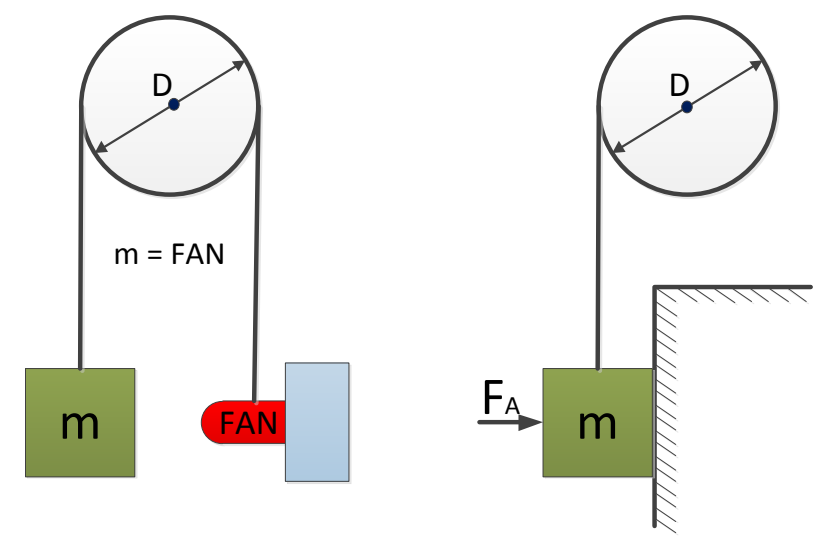

Şekil 4. Hareketli fan makara sistemi.

Şekil 1'deki sistemin tasarımında ve servo motorun seçiminde sistemin ataletini bulmak için 2.1 eşitliği kullanılmaktadır.

$$
J_{w}=\left[D^{2} \times\left(m_{1}+m_{2}\right) / 4\right] \times 10^{6}\left(\mathrm{kgm}^{2}\right)
$$

Burada $m_{1}$ fan ağırlığı, $m_{2}$ karşıt yük ağırlığı, $D$ makara çapını sembolize etmektedir. Servo motorun yük torkunu bulmak için 2.2 eşitliği kullanılmaktadır.

$$
T_{L}=\left(\mu \times F_{A}+m \times g\right) \times D /(2 i)
$$

Burada $F_{A}$ dış kuvveti, $\mu$ sürtünme katsayısını, $g$ yerçekimi ivmesini, $m$ toplam kütleyi, $D$ makara çapını $i$ ise dişli oranını sembolize etmektedir. Servo motor seçiminde yük hareket gücünü bulmak için 2.3 eşitliği kullanılmaktadır.

$$
P_{o}=\left(2 \times \pi \times n_{M} \times T_{L}\right) / 60
$$

Burada $T_{L}$ yük torku, $n_{M}$ motor şaft rotasyon hızı, $J_{L}$ yük atalet momenti ve $t_{a}$ hızlanma zamanını sembolize etmektedir. Servo motorun yük hızlandırma gücünü bulmak için 2.4 eşitliği kullanılmaktadır.

$$
P_{a}=\left(2 \times \pi \times n_{M} / 60\right)^{2} \times\left(J_{L} / t_{a}\right)
$$

Servo motor seçiminde, $T_{L} \leq$ nominal tork, $J_{L} \leq$ nominal yük atalet momenti, kriterleri dikkate alınarak seçim yapılmalıdır. Fanlar $50 \mathrm{~cm}$ 'den $2 \mathrm{~m}$ yüksekliğe kadar hareket edebilmektedir. Her bir araç için hareketli fanlar aşağıdan yukarıya ve yukarıdan aşağıya bir kez hareket etmektedir. Burada yükseklik farkı 1,5 m'yi bulmaktadır. Fanların bulunduğu kirişin toplam ağırlığı yaklaşık 150 kg'dır. Sisteme karşıt ağırlık konulmadığında her bir araç için bir kolonda 2250 J'lük bir enerji zayi olmaktadır. Toplamda 2 adet kolon olduğundan 4500 J'lük $(1,25 \mathrm{Wh})$ bir enerji kaybı yaşanmaktadır. Sistemin günde yüzlerce araç testi yaptığ1 düşünüldüğünde, bu tasarruf oranı daha da iyi anlaşılmaktadır. Ayrıca sistemde karşıt ağırlık bulunduğunda servo motor, sistemi aşağı yukarı hareket ettirirken sıfıra yakın bir atalete karşı koymaktadır. Sistemde karşıt ağırlık olmadığında motorların 150 kg'lık bir kütleyi kaldırması ve o noktada sabit tutması gerekmektedir. Bu da yaklaşık 4 kat daha güçlü bir motor ve ekstra bir redüktör grubu (sistemi istenilen konumda sabit tutmak için) kullanılması anlamına gelmektedir. 2.1, 2.2, 2.3, 2.4 eşitlikleri esas alınarak sistem tasarımı yapıldığında $1 \mathrm{~kW}$ gücüne sahip bir servo motor kullanılması uygun görülmektedir.

\subsection{Hareketli Fan Sisteminde Karşı Ağırlığın Seçimi (Counterweight Selection in Moving Fan System)}

Karşı ağırlık, hareketli fan sisteminde fan ağırlığını dengeleyerek motorun daha verimli çalışmasını ve daha az güç harcanmasını sağlamaktadır. Karşı ağırlık, fanın sürekli olarak eşit momentler oluşturmasını sağlar. Böylece motor sabit güç harcama eğrisine sahip olmakta ve motor verimliliği artmaktadır. Sistemde karş1 
ağırlık, kullanılan fan kirişinin ağırlı̆̆ına eşit olarak $(150 \mathrm{~kg})$ alınmıştır. Böylelikle sistemin minimum yükte çalışması ve düşük enerji tüketimi sağlanmaktadır.

\subsection{Fan Gücü ve Fan Hava Debisi Hesabı (Fan Power and Fan Air Flow Calculations)}

Sistemdeki tüm fanların güçlerinin hesaplanmasında 2.5 ve 2.6 eşitlikleri kullanılmaktadır $[10,11]$.

$$
\begin{aligned}
& N=\left(Q \times \Delta P_{t}\right) /(3600 \times 1000)(k W) \\
& N_{m}=\left(Q \times \Delta P_{t}\right) /\left(3600 \times 102 \times n_{M}\right)(k W)
\end{aligned}
$$

Bu formüllerde $Q$ fan hava debisini, $\Delta P_{t}$ ise fan basınç artımını simgelemektedir. Hesaplamalarda $\Delta P_{t}=$ 9,8 $\mathrm{Pa}$ olarak alınmaktadır. Sistemdeki tüm fanların debi hesabında ise 2.7 eşitliği kullanılmaktadır.

$$
Q=v \times A
$$

Burada $v$ fan hızını, $A$ ise fan kesitini simgelemektedir. Tasarımda 2.5, 2.6 ve 2.7 numaralı eşitlikler kullanılarak, hareketli fanlar ve yan fanlar için toplamda 4 adet $2,2 \mathrm{~kW}$ gücünde, $1400 \mathrm{~d} / \mathrm{d}$ devir sayısına sahip ve $6000 \mathrm{~m} 3 / \mathrm{h}$ debiye sahip fan seçilmiştir. Püskürteç bölümündeki giriş ve çıkışta kullanılan fanlar ise 2 adet $0,18 \mathrm{~kW}$ değerinde $1430 \mathrm{~d} / \mathrm{d}$ devir sayısına sahip $1800 \mathrm{~m}^{3} / \mathrm{h}$ debiye sahiptir.

\subsection{Nozzle Sistemi Tasarımı (Nozzle System Design)}

Nozzle'lar sistemde suyun istenilen noktalara yönlendirilmesini sağlayan elemanlardır. Suyun araca istenilen açı ve basınç değerlerinde ulaştırılmasını sağlar. Aracın sızdırma ihtimali olan körük, conta, fitil gibi kısımları hedef alınarak basınçlı su püskürtülür. Nozzle sistemi tasarlanırken nozzle sistemi süreklilik denklemi olan 2.8 eşitliği kullanılmaktadır [12].

$$
A_{1} \times v_{1}=A_{2} \times v_{2}
$$

Burada $A_{1}$ ve $A_{2}$ su giriş ve çıkış borularının kesitini ifade ederken, $v_{1}$ ve $v_{2}$ suyun giriş ve çıkış hızlarını ifade etmektedir. Suyun çıkış hızını belirlemek için 2.9 eşitliği kullanılmaktadır [9].

$$
Q=P \times \eta / \Delta P
$$

Bu formülde çıkış hızı m³/s cinsindendir. Formülde $P$ pompa gücünü, $\eta$ pompa verimini, $\Delta P$ ise giriş ve çıkış arasındaki basınç değişimini simgelemektedir. $\Delta P$ 'yi bulmak için 2.10 Bernoulli eşitliği kullanılır.

$$
\Delta P=\left(v_{2}^{2}-v_{1}^{2}\right) / 2+\Delta z \times g+\Delta P_{\text {statik }} / d
$$

Bernoulli eşitliğinde $v_{1}$ ve $v_{2}$ suyun giriş ve çıkış hızlarını, $\Delta z$ suyun yükseklik değişimini, $g$ yerçekimi katsayısını, $d$ kullanılan sıvının yoğunluğunu, $\Delta P_{\text {statik }}$ ise statik durumdaki basınç değişikliğini ifade etmektedir.

Sistemde 2.8, 2.9 ve 2.10 numaralı formüller kullanılarak yapılan hesaplamalarla, sistemin üst kısmı için araçların ortalama uzunlukları temel alınarak, toplamda yan yana 25 adet 2,5 metre uzunluğunda boru yerleştirilmiştir. Boruların üzerlerine $20 \mathrm{~cm}$ aralıklarla her bir boruya 12 adet nozzle konulmuştur. Nozzle su basıncı ve debisi sabittir ve 2 bar basınç değerine ayarlanmıştır.

Sistemin sağ ve sol kısmına ise 25 adet 3 metre uzunluğunda boru yerleştirilerek boruların üzerlerine üst kısımda olduğu gibi $20 \mathrm{~cm}$ aralıklarla 15 adet nozzle konulmuştur. Ayrıca üst kısımdaki borular, sağ ve sol kısımdaki borulara $90^{\circ}$ 'lik dirsekler ile bağlanarak suyun bütün borulara ulaşması sağlanmaktadır. Buradaki su basıncı ve debisi sabit, 10 bar olacak şekilde ayarlanmaktadır. 
Taşıta püskürtülen suyun nozzle'dan çıkış açısı 70 derecedir. Üst ve yan kısımlarda bulunan nozzle'ların tamamından eş zamanlı şekilde su çıkışı sağlanmaktadır.

\subsection{Pompa Gücü ve Verimliliği Hesabı (Pump Power and Efficiency Calculation)}

Pompa seçiminde pompa motor gücü için 2.11 eşitliği kullanılmaktadır.

$$
P=[(Q \times h \times \rho) /(367 \times \eta)] \times f_{\text {emniyet }}
$$

Eşitlik 11'de $Q$ debiyi, $h$ sıvıyı basma seviyesini, $\rho$ akışkanın yoğunluğunu, $\eta$ pompa verimini simgelemektedir. $f_{\text {emniyet }}$ değeri motorun gücüne göre,

$P<15 \mathrm{~kW}$ lık mil gücü için $f_{\text {emniyet }}=1,15$

$P \leq 15 \mathrm{~kW}$ lık mil gücü için $f_{\text {emniyet }}=1,1$

$P>15 \mathrm{~kW}$ lık mil gücü için $f_{\text {emniyet }}=1,05$

olarak seçilmelidir. Pompanın hidrolik gücü ise 2.12 eşitliği ile hesaplanmaktadır.

$$
P_{H}=Q \times h \times \rho \times g
$$

Burada, $Q$ pompa debisini, $h$ pompa basma yüksekliğini, $\rho$ sıvı yoğunluğunu, $g$ yerçekimi sabitini ifade eder. Pompanın verimini bulmak için ise 2.13 eşitliği kullanılmaktadır.

$$
\eta=P_{H} / P_{M}=Q \times h \times \rho \times g / P_{M}
$$

Burada $P_{H}$ pompanın hidrolik gücünü, $P_{M}$ ise mekaniksel gücü simgelemektedir. Tasarımda 2.11, 2.12 ve 2.13 numaralı formüller kullanılarak nozzle sisteminde ihtiyaç duyulan 10 bar mertebesindeki basınçlı suyu sağlayabilmek için $11 \mathrm{~kW}(15 \mathrm{HP})$ gücünde $40 \mathrm{~m}^{3} / \mathrm{saat}$ debi değerine sahip bir pompa kullanılmıştır.

\section{BASINÇLI SU TEST OTOMASYON SISTEMI (PRESSURIZED WATER TEST AUTOMATION SYSTEM)}

Operasyon başlamadan önce gerekli işlemlerin yapılması gerekmektedir. İlk olarak önceki istasyondan "hazır" bilgisinin alanda bulunan kontrolcüye gelmesi gerekmektedir. Sonrasında acil stop bilgisine bakılır. Ardından "havuz hazır" ve "tanktaki su maksimum seviyede" bilgilerinin gelmesi gerekmektedir. Son olarak sistemin "başlangıç" pozisyon kontrolü yapılmaktadır. Bu işlemlerin ardından operasyon başlatılmaya hazır konumda olmaktadır. Sayılan şartlardan herhangi birinin sağlanamaması durumunda, bu şartlar sağlanana dek operasyon başlatılamamaktadır. Şekil 5'de araç basınçlı su test sistemi genel şeması görülmektedir.

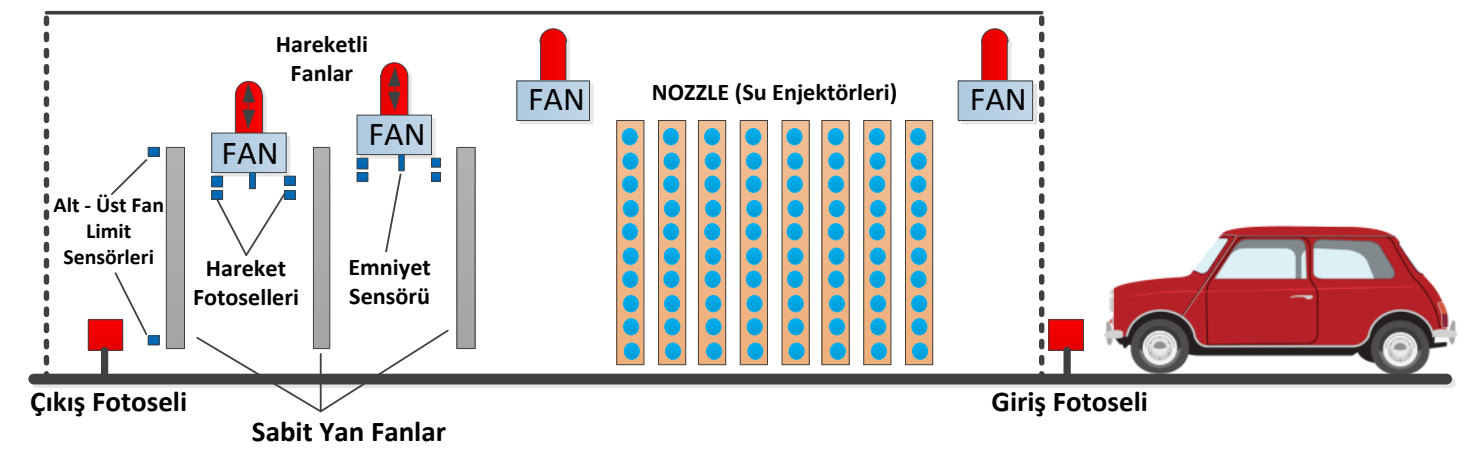

Şekil 5. Genel sistem şemast.

Başlangıç şartlarının hepsi sağlandıktan sonra test işlemi başlatılmaktadır. Giriş fotoseli aracı algılayınca giriş fanı çalışarak aracın üzerinde önceki proseslerden kalabilecek olası partikülleri ve parçacıkları uzaklaştırmaktadır. Ardından araç ilerleyerek, araca belirlenen basınç değerinde su püskürten enjektörlerin 
bulunduğu alana gelmektedir. Burada araç, içerisine herhangi bir noktadan su alıp almadığını belirlemek için bir süre, her noktadan basınçlı suya maruz bırakılmaktadır. Eğer araçta herhangi bir izolasyon problemi var ise, bu aşamada aracın içerisine su girmesi beklenmektedir. Basınçlı su püskürtme işleminden sonra araç ilerleyerek çıkış fanına ulaşmaktadır. Su püskürtme işleminin ardından, aracın sonraki istasyona kuru bir şekilde ulaşmasını sağlamak amacıyla kurutma işleminin gerçekleştirilmesi gerekmektedir.

Kurutma işlemi ile hem sonraki istasyon alanlarının ıslanmasının önüne geçilmekte hem de test işleminde kullanılan suyun tekrar kullanılarak çevreci bir çözüm sunulması sağlanmaktadır. Sabit çıkış fanından sonra üç tarafı kapalı istasyonun yanlarında sabit, üstünde ise hareketli fanlar yardımıyla kurutma işlemine devam edilmektedir. Esas olarak bu işlem ile aracın üzerindeki suyun buharlaştırılarak değil yerdeki kanallara doğru sıyrılarak geri dönüştürülmesi hedeflenmektedir. Bu nedenle aracın üstünde konumlandırılan tepe fanları, üzerlerindeki sensörler yardımıyla aracın formuna göre yukarı aşağı hareket ederek suyu aracın üzerinden sıyırmaktadır.

Araç kuru bir şekilde çıkış fotoselinden geçerek işlemin sonlandığı ve bir sonraki istasyona doğru harekete hazır olduğu bilgisi verilmektedir. Aracın istasyondan çıkmasından sonra operatör aracın kapılarını açarak ilgili noktaların sızdırmazlık kontrollerini yapar. Bu döngü gelen diğer araçlar için de tekrarlanır. Şekil 6' da genel otomasyon sistem şeması verilmektedir.

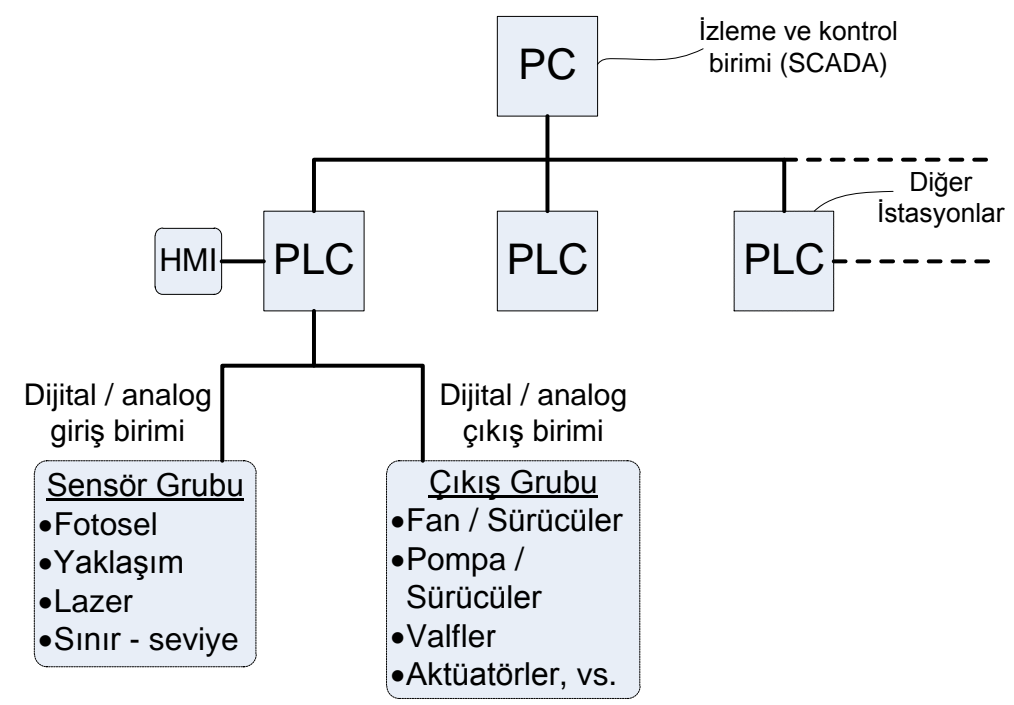

Şekil 6. Otomasyon sistem şemast.

Fabrikadaki tüm üretim aşamaları bir SCADA sistemi üzerinden görüntülenebilmektedir. Su sızdırmazlık test platformu özelinde bakıldığında, sistem Mitsubishi Q serisi bir PLC tarafindan kontrol edilmektedir. Aynı zamanda güncel sistemlerde sıklıkla kullanılan HMI panel (Mitsubishi GOT serisi) üzerinden operatörün sistemi anlık olarak izlemesi ve gerektiğinde müdahale etmesi sağlanmaktadır. Sistemde; fotoseller, yaklaşım sensörleri, lazer sensörler ve sınır - seviye sensörleri gibi birçok analog ve dijital giriş bulunmaktadır. Bu sensörlerden gelen bilgiler PLC tarafından işlenmekte ve fan, aktüatör, valf, pompa ve sürücü gibi bileşenlerin kontrolü sağlanmaktadır.

\subsection{Sistemin Otomatik Çalışma Durumu (Automatic Mode Operation of the System)}

Sistem önce başlama komutuyla hazır hale gelir ve proses çalışmaya başlar. Sistemdeki ilk giriş fotoseli aracı gördükten sonra ön kısımda yer alan fanlar çalışmaya başlar. Sistemin elektriksel olarak aniden yüklenmemesi için alıcılar kademeli bir şekilde devreye girer. Giriş fanlarının ardından nozzle su püskürtmeye başlar, yandaki ısıtıcılar ve hareketli fanlar da sırasıyla çalışmaya başlar.

Hareketli fanların çalışma mesafeleri ve sonlandırma sensörleri sistem üzerinde yer almaktadır. Ayrıca fanların aracın üzerine çarpma veya düşme riski göz önüne alınarak emniyet sensörü ve frenleme devresi tasarlanmıştır. Hareketli fanların aracın yüzeyine paralel hareket edebilmesi için araç varlığının kontrolü 
sensör setleriyle yapılmıştır. Başlangıçta fanlar mekanik olarak en uzak sensöre doğru hareket eder. Alttaki iki sensör ile arabanın mesafesi tespit edilir ve yaklaşıp yaklaşmadığı bilgisi alınır. Sensör aracı gördükten sonra, iki sensörden yukarıda olanı aracı görmeyene kadar fan yukarı hareket ettirilir. Sistem böylece tavan bölgesini kurutmuş olur.

Sistem tavan bölgesini geçince ikili sensör grubundan alttaki sensör aracı görmez ve fan alttaki sensörü görene kadar aşağı indirilir. Bu arada araç kurutma işlemi bitmiş olur ve sistem alt sensöre kadar ilerler. Araç çıkıştaki 2. fotoseli görünce işlem biter. Diğer araçlarda da döngü aynı şekilde devam eder. İlk girişteki fotosel araç algılamadığı zaman sistemdeki bir aracın test süresi kadar bekler. Ardından sistem kendini otomatik olarak bekleme durumuna alır. Sistem bekleme modunda iken fanlar ve su püskürtme sistemi stand-by pozisyonunda bekletilmektedir.

Şekil 7 ve Şekil 8'de araç basınçlı su test sisteminin çalışma algoritması verilmektedir.

\subsection{Sistemin Manuel Çalışma Durumu (Manual Mode Operation of the System)}

Sistemin manuel kontrolü pano üzerindeki dokunmatik panelden yapılmaktadır. Dokunmatik panel menüsünden; sabit üst fanlar, sabit yan fanlar, hareketli fanlar, hareketli fan hareketleri (sensörler aktif), pompaların manuel kontrolleri yapılabilir. Manuel çalışma modunda sistem aşağıda belirtildiği gibi çalışır.

- Hareketli fanlar üzerindeki hareket sensörleri aktif değildir

- Havuz seviye belirleyiciler devre dışı kalır ve su seviyesi maksimum sınıra ulaştığında veya minimum sınıra indiğinde alarm verir

- Havuzdaki su seviyesi minimum sinırda ise su sirkülasyon pompaları manuel olarak çalıştırılamaz

- Tank dolumu otomatik yapılmaz, manuel dolum yapmak gerekir

- Hareketli fanlar üzerindeki emniyet anahtarları aktiftir ve herhangi bir çarpma durumunda hareketli fanlar üst sınıra kadar çıkar ve reset yapıldıktan sonra çalıştırılabilir. Hareketli fanlar otomatik çalışma modunda olduğu gibi (sensörler aktif) çalışırlar. Hareketli fanlar üzerindeki fotoseller kesildikçe fanlar hareket eder.

- Hareketli fanları sabit olarak aşağı veya yukarı hareket ettirmek istediğimiz herhangi bir noktada tutmak için ara modda çalıştırmak gerekmektedir. (Ara mod: Manuel veya otomatik modun seçili olmadığı durum). Bu modda hareketli fanlar üzerindeki sensörler aktif değildir. Fanlar manuel aşağı veya yukarı hareket ettirilebilir. Herhangi bir çarpma durumunda emniyet anahtarları aktif durumda olmakta ve fanları yukarı üst sınıra kadar çıkarmaktadır. Reset işleminden sonra tekrar hareket ettirilebilir. Hareketli fanların manuel olarak çalıştırılabilmesi (ara mod) için ;

$>$ Kabin içerisinde araç olmaması,

$>$ Konveyörün duruyor olmas1,

> Oto start'a basılmamış olması,

- Manuel mod veya otomatik modun seçilmemiş olması,

> Acil stop'un bas1lı konumda olmamas1 gerekmektedir.

- Acil durum butonlar manuel çalıştırmada da aktif durumdadırlar.

- Kabin içerisindeki araç sayısını sıfırlamak için dokunmatik ekrandan sayıcı sıfırlanır ve çıkış fotoseli anlık olarak kesilir. 


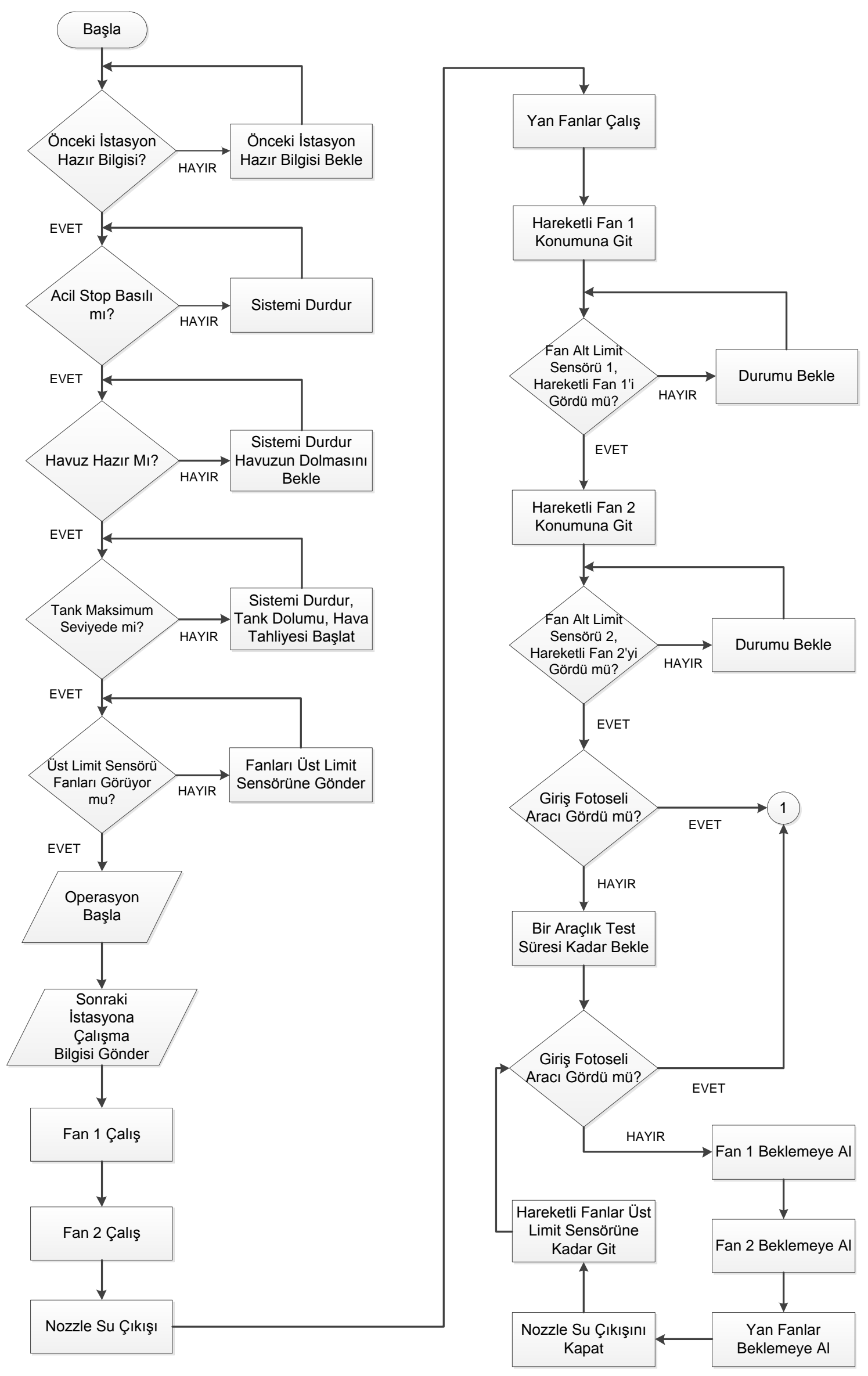

Şekil 7. Araç basınçlı su test sistemi çalışma algoritması. 


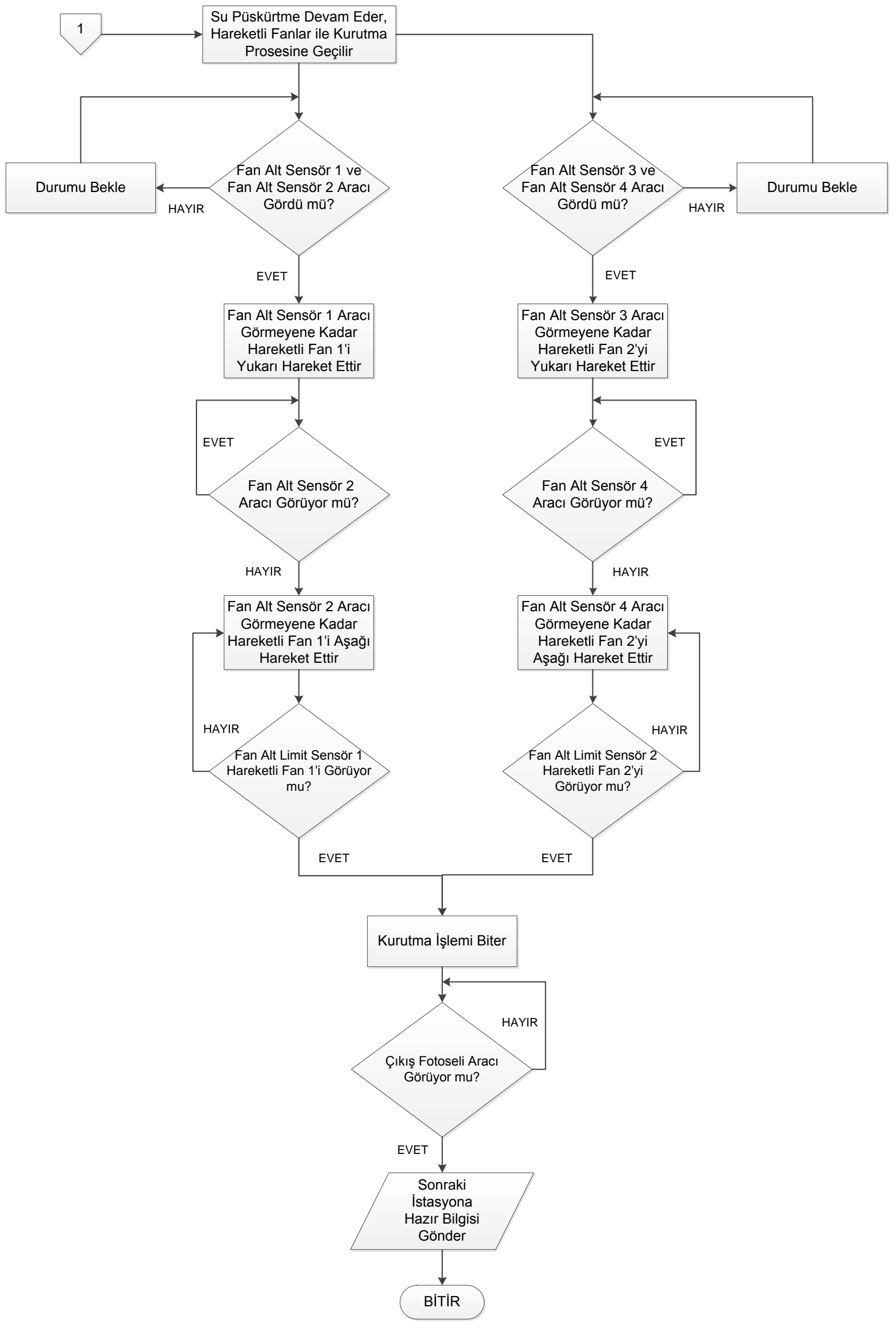

Şekil 8. Araç basınçlı su test sistemi çalışma algoritması. 


\subsection{Tankın Çalışma Durumu (Operation of the Water Tank)}

Tankın içerisinde bulunan alt ve üst sensörler yardımıyla tank içerisindeki su seviyesi belirlenir. Su seviyesi alt sınıra ulaştığı zaman sistem otomatik durur ve tank dolumu başlar, bununla beraber mekanik olarak içerideki hava dışarıya atılır. Tank dolumu üst sensöre, yani maksimum seviyeye kadar devam eder. Şekil 9'da havuz sistemin şeması görülmektedir.

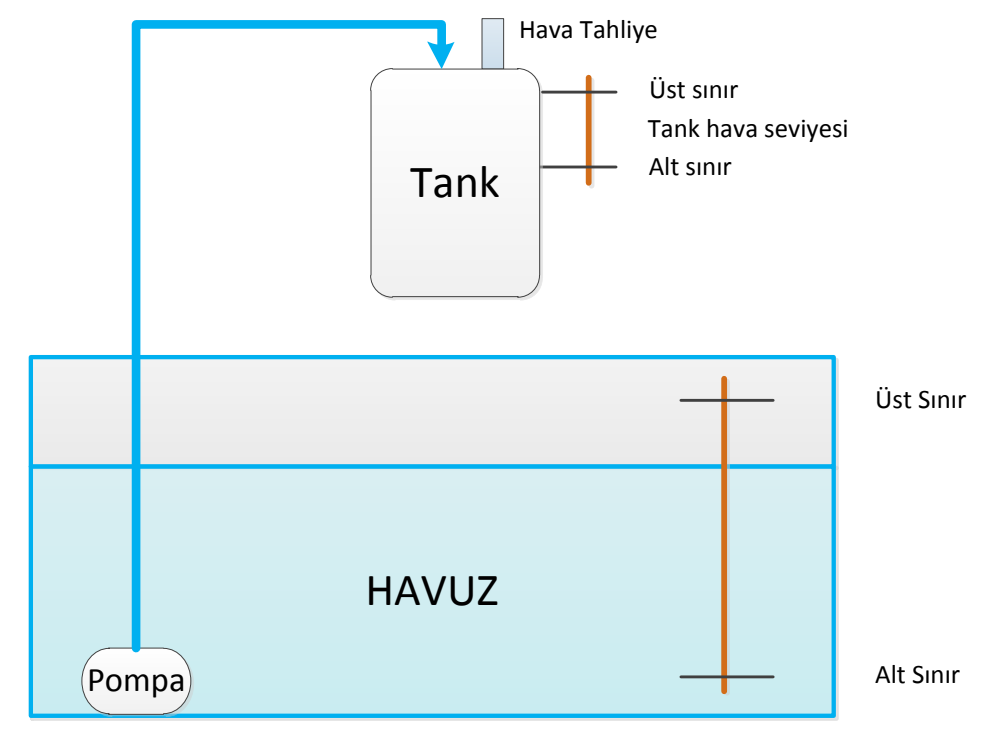

Şekil 9. Havuz ve tank dolum sistemi.

Üst sensöre gelince dolum durur ve sistem kaldığı yerden devam eder. Tank suyunu havuzdan alır. Havuz konveyörün alt kısmında bulunur ve kullanılan suyun tekrar havuza gönderilmesi sağlanır. Bu şekilde sistemde \% 80'e varan su tasarrufu sağlanır. \% 20'lik kısım ise filtrasyon sırasında atılarak, kurutma işleminde buharlaşarak sistemden atılmaktadır. Az bir miktar su da aracın üzerinde kalmaktadır.

\section{SONUÇ (CONCLUSION)}

Araç basınçlı su testi sistemi su sızdırmazlık kaçakların tespitinde makina, elektrik ve bilgisayar sistemlerinin kolektif yapılanması ile oluşmaktadır. Sistemin tamamı dikkate alındığında, yapılan püskürtme ile araçlardaki kaçağın en hızlı yolla tespit edilmesi sağlanmaktadır. Ardından yapılan kurutma işlemi ile aracın ıslak olduğu zaman hava ile temasından meydana gelebilecek renk bozulmalarına karşı, görüntü ve çevre kirliliğine karşı önlem alınmaktadır. Kurutma işlemi yapılmadığında, aşırı nemden dolayı fabrikada bulunan cihaz ve teçhizatın oksidasyonu söz konusu olmaktadır. Bu işlem sayesinde hem zamandan hem de iş gücünden tasarruf edilmektedir. Ayrıca hareketli fanlar sayesinde aracın her bölgesine ulaşılıp tam bir kurutma işlemi gerçekleştirilmektedir.

Ayrıca daha az enerji sarfiyatı ve daha küçük motorlar ile sistemin çalıştırılması, kurutma işleminde kullanılan fanlar ile aynı ağırlıkta karşıt ağılıkların konulmasıyla sağlanmaktadır. Böylece geleneksel sabit fanlı, karşıt ağırlıksız kurutma sistemlerine göre yaklaşı \% 75 enerji tasarrufu sağlanmaktadır. Elektriksel olarak bakıldığında ise genel sistem verimi \% 40 oranında artmaktadır. Ayrıca sistemin kurulum aşamasında seçilen motorların bir kısmı daha düşük güçte seçilmektedir. Fanların hareketini sağlayan motorların güç değerleri 3/4 oranında küçülmektedir.

Tasarlanan sistemde, konveyörün alt kısmına yerleştirilen havuz sayesinde, yıkama suyunun tekrar kullanılması sağlanarak daha çevreci bir sistem oluşturulmaktadır. Buradaki geri dönüşüm ve tasarruf oranı ise $\% 80$ civarındadır.

Kurulan sistem genel olarak değerlendirildiğinde, klasik basınçlı su yıkama sistemlerine göre daha verimli ve tasarruf sağlayan bir sistem gerçekleştirilmiştir. Sistemde kurutma fanlarının kullanılması, kurutma 
fanlarının daha az enerji ile hareketini sağlamak için karşıt ağırlıkların kullanılması ve atık suyun geri dönüştürülerek tekrar kullanılması sistem verimini artırmakta ve daha çevreci bir uygulama olmasını sağlamaktadır.

\section{TEŞEKKÜR (ACKNOWLEDGEMENT)}

Koray ERHAN, "Türk Akademisyenler için Doktora Bursu" kapsamında ASELSAN tarafindan desteklenmektedir. Sisteminin kurulumunu gerçekleştiren Marmara Teknik Makina firmasına ve Hüseyin Salihoğlu'na katkılarından dolayı teşekkürlerimizi sunarız.

\section{KAYNAKLAR (REFERENCES)}

[1] R. Bayındır, O. Kaplan, C. Bayyiğit, Y. Sarıkaya, M. Hallaçlığlu PLC ve SCADA kullanılarak bir endüstriyel sistemin otomasyonu. Erciyes Üniversitesi Fen Bilimleri Enstitüsü Dergisi, 27:1 (2011) 107-115.

[2] M. Ayaz, K. Erhan, E. Taşdemirci, M. Karaçor, Bir Katı Atık Bertaraf Tesisi için Otomasyon Sistem Tasarımı ve Uygulaması. Düzce Üniversitesi Bilim ve Teknoloji Dergisi, 2 (2014) 178-190.

[3] R. Bayındır, Ş. Demirbaş, A. Bektaş, İ. Çolak, Bir endüstriyel işletmede elektrik enerjisinin izlenmesi. Erciyes Üniversitesi Fen Bilimleri Dergisi, 24:1 (2008) 154-164.

[4] Ö. Aydoğdu, M.G. Hasırcı, H. Akçay, Bir Entegre Et Tesisinde SCADA Tabanlı Endüstriyel Kontrol Uygulaması. Elektrik-Elektronik ve Bilgisayar Mühendisliği Konferansı, 2008.

[5] M. Ayaz, Erhan K., A. Aktaş, E. Özdemir, H. Salihoğlu, Araç Yakıt Tankı Montajı için Otomasyon Sistem Tasarımı ve Uygulamas1, Düzce Üniversitesi Bilim ve Teknoloji Dergisi, 3 (2015) 357-366.

[6] E. Doruk, M. Pakdil, G. Çam, İ. Durgun, U. C. Kumru, Otomotiv Sektöründe Direnç Nokta Kaynağı Uygulamalar1," Mühendis ve Makina, 57: 673, (2016) 48-53.

[7] E. Doruk, M. Pakdil, G. Çam, İ. Durgun, U. C. Kumru, Otomotiv Sektöründe Direnç Nokta Kaynağı Tofaş Uygulamaları. IX. Ulusal Kaynak Kongresi, 2015.

[8] H. Küçük, Otomasyon yönetiminde insan faktörü ve türk otomotiv sektöründe bir uygulama. Yüksek Lisans Tezi, İstanbul Teknik Üniversitesi, Fen Bilimleri Enstitüsü, İstanbul, (1995) 117.

[9] B.B.L.V. Deepak, P. Shubhankar, A. Kumar, A. Mahil, A. Sahoo, Design Of Car Washing Machine, Industrial Design Project Report, Methodology, (2014) 1-20.

[10] http://deneysan.com/Content/images/documents/ havalandirma-4_39143832.pdf., (30.03.2017)

[11] M. Bilgili, E. Şimşek, Y. Polat, A. Yaşar, Havalandırma sistemleri, Adana Meslek Yüksekokulu Yayınları, No:1 (2005).

[12] https://www.ia.omron.com/products/category/sensors/proximity-sensors/., (30.03.2017) 